\title{
Phenol Removal from Aqueous Environment by Adsorption onto Pomegranate Peel Carbon
}

\author{
Mojtaba Afsharnia ${ }^{1}$, Mahdi Saeidi², Amin Zarei ${ }^{3}$, Mohammad Reza Narooie ${ }^{4}$, Hamed Biglari ${ }^{5}$
}

${ }^{1}$ Ph.D. of Environmental Health, Assistant Professor, Department of Environmental Health Engineering, School of Public Health, Social Development \& Health Promotion Research Center, Gonabad University of Medical Sciences, Gonabad, Iran

${ }^{2}$ M.Sc. of Environmental Health, Instructor, Department of Environmental Health Engineering, School of Public Health, Torbat Heydarieh University of Medical Sciences, Torbat Heydarieh, Iran

${ }^{3}$ M.Sc. of Environmental Health, Senior Lecturer, Department of Environmental Health Engineering, School of Public Health, Mashhad University of Medical Science, Mashhad, Iran

${ }^{4}$ M.Sc. of Environmental Health, Senior Lecturer, Department of Environmental Health Engineering, School of Public Health, Iranshar University of Medical Sciences, Iranshar, Iran

${ }^{5}$ M.Sc. of Environmental Health, Senior Lecturer, Department of Environmental Health Engineering, School of Public Health, Social Development \& Health Promotion Research Center, Gonabad University of Medical Science, Gonabad, Iran

\section{Type of article: Original}

\begin{abstract}
Introduction: Phenol and its derivatives are the most common poisonous compounds which are stable in aqueous media and lead to many health issues. In this study, application of the carbon resulted from pomegranate peel is investigated in removal of phenol by adsorption method.

Methods: to perform this cross-sectional study, first, samples of phenol with concentrations of 10 to $100 \mathrm{mg} / \mathrm{L}$ were prepared for six months in 2016. Then, the impacts of parameters such as $\mathrm{pH}$, adsorbent dosage, contact time, and initial concentration of phenol in adsorption process were investigated independently in Gonabad Chemistry Lab using a spectrophotometer at $505 \mathrm{~nm}$ as the wavelength. Furthermore, adherence of the samples to the isotherm models of Langmuir and Freundlich was determined by Excel 2016 and descriptive statistical methods were then reported.

Results: The obtained results demonstrated a maximum adsorption capacity (ash) of $148.38 \mathrm{mgg}-1$ at $\mathrm{pH}$ 7, initial concentration of $100 \mathrm{mg} \mathrm{L}^{-1}$, and temperature of $23 \pm 2{ }^{\circ} \mathrm{C}$. The phenol removal rate was found to correlate directly to the adsorbent dosage and contact time, and inversely to the initial concentration of phenol. In addition, the investigations showed that the adsorption of phenol on the pomegranate peel ash follows the Freundlich model well with a correlation coefficient of R2 0.9056 .

Conclusion: Pomegranate peel ash could be used as an efficient and low-cost adsorbent for phenol removal from aqueous media.
\end{abstract}

Keywords: Adsorption, Aqueous solution, Pomegranate peel, Activated carbon, Freundlich, Langmuir isotherm

\section{Introduction}

Presence of toxic and stable compounds in the environment has led to major health and environmental problems. Phenol is one of the most common contaminants found in wastewater of industries such as resin, plastics, explosives, steel, leather, etc. The phenol released from these industries causes contamination of the environment, in particular water sources. This compound forms compounds such as chlorophenol which are classified as priority pollutants due to their certain features such as high toxicity, carcinogenicity, impact on the taste and odor, accumulative, low

\section{Corresponding author:}

Hamed Biglari, Department of Environmental Health Engineering, School of Public Health, Social Development \& Health Promotion Research Center, Gonabad University of Medical Science, Gonabad, Iran.

Tel: +98.5157225027, Fax: +98.5157223814, Email: Biglari.h@gmu.ac.ir

Received: June 21, 2016, Accepted: September 19, 2016, Published: November 2016

iThenticate screening: August 28, 2016, English editing: October 12, 2016, Quality control: November 04, 2016

(C) 2016 The Authors. This is an open access article under the terms of the Creative Commons Attribution-NonCommercialNoDerivs License, which permits use and distribution in any medium, provided the original work is properly cited, the use is noncommercial and no modifications or adaptations are made. 
biodegradability potential, and many other adverse effects on human health and other living things, and has attracted the attention of many environment experts $(1,4,5)$. The health effects caused by exposure to phenol can be determined by the amount of the phenol adsorbed as well as the contact time. These effects could vary from mucosal and skin irritation and burns to systemic toxicity as well as decreased blood pressure, increased heart rate and coma (6). Studies have shown that consumption of 8 to $15 \mathrm{mg}$ of phenol could result in death (7). Phenol will quickly enter the circulatory system of the livings due to its high permeability, regardless of the manner of exposure (skin contact or mucosal adsorption) (8). The presence of phenol in drinking water treated with chlorine leads to formation of side products and makes the water non-potable and harmful by giving it an unpleasant taste and odor (9). In addition, considering the carcinogenicity potential of phenol to humans and other living things, remarkable concerns are raised even in low concentrations (10). Toxic effects of phenol include penetration into the cells and cytoplasm, clotting and damaging the crucial cells in the body (10-13). Thus, detection and determination of the concentration of phenolic compounds in wastewater and their subsequent removal in all steps of production, treatment and evacuation of wastewater into the sources appears to be necessary. Regulations of World Health Organization limits the phenol concentration to below $0.1 \mu \mathrm{g} \mathrm{L}^{-1}(\mathrm{ppb})$ and according to the regulations of MOEF (Ministry of Environment and Forests) its maximum allowed amount in the output of the industries and surface water is considered $1 \mathrm{mg} \mathrm{L}^{-1}(10,14)$. When releasing wastewater into the surface water and for agricultural and drinking uses, the maximum allowed amount of phenol concentration is determined as $1 \mathrm{mg} \mathrm{L}^{-1}$ and $0.5 \mu \mathrm{g} \mathrm{L}^{-1}$ by Environmental Protection Agency Standard and Standard Institute of Iran, respectively $(15,16)$. Various processes are used for removal of phenolic compounds from aqueous media, most common of which include extraction, adsorption with activated carbon, steam distillation, electrochemical methods, radiation, advanced oxidation, chemical oxidation, adsorption, and biological treatment. The majority of these methods suffer from disadvantages such as high cost of treatment, the need for additional filtration, production of dangerous side products, low efficiency and applicability for a limited range of contaminant concentrations $(17,18)$. The adsorption process is one of the most common methods applied widely for removal of organic and inorganic contaminants from aqueous solution (19). The adsorption process is one of the simplest, most efficient, and cost effective alternatives for removal of phenol from aqueous media which is capable of removing most forms of organic material (19-23). The low costs and prevalence of the utilized adsorbents such as agriculture waste has led this method to be widely investigated and applied for phenol removal. Activated carbon, clay, polymer materials, sludge, zeolite, chitosan and chitin are some of the absorbents used for phenol removal (24-31). Commercial activated carbon demonstrates high efficiency for removal of phenol, however, considering high costs of the preparation and reduction of commercial activated carbon, it is not cost effective to use. This has compelled researchers to try to develop novel cost effective adsorbents (32). Hence, in this study, the application of pomegranate peel ash is investigated as an adsorbent for removal of phenol from aqueous solutions.

\section{Material and Methods}

This study is carried out in Gonabad in 2016. All chemicals used in this study were purchased from Merc and Aldrich Companies. Dried peel of pomegranate was supplied from Ferdows city. To obtain carbon from these peels, they were first washed with clean water and then with deionized water. They were then dried in an oven at $105{ }^{\circ} \mathrm{C}$ for sixty minutes. In the next step, they were ground as finely as possible and placed in an oven at $450{ }^{\circ} \mathrm{C}$ for sixty minutes to obtain the carbon. The obtained carbon was ground in a porcelain mortar. It was then sieved using standard ASTM sieves with the size in the range of 0.15-0.85 mm. Finally, the samples were cooled and kept in a desiccator. To determine the optimum parameters for any kind of adsorbent, the experiments were performed on samples of water contaminated with phenol with concentrations of 10 to $100 \mathrm{mg} \mathrm{L}^{-1}$, which were prepared from stock solution of 1000 $\mathrm{mg} \mathrm{L}^{-1}$ of phenol, and initial $\mathrm{pH}$ values of 2 to 12 by addition of 0.1 and 1 normal sulfuric acid and sodium hydroxide. The monitoring took place by a Denver Ultra basic- UB $10 \mathrm{pH}$ meter made in USA. The adsorbent doses ranged within 0.1 to $0.7 \mathrm{mg} \mathrm{L}^{-1}$ at $23 \pm 2{ }^{\circ} \mathrm{C}$. Following addition of the adsorbent to the solutions in Erlenmeyer flasks, the mixture was stirred at constant temperature of $30 \pm 1{ }^{\circ} \mathrm{C}$ at stirring rate of $150 \mathrm{rpm}$ using a stirrer equipped with incubator, model KS 4000i control, made by IKA Company of Germany. This process was repeated twice. Finally, the sampling of phenol concentration took place using a T80 UV/Vis spectrometer in 15 to 210 minutes after separation of the adsorbent by centrifuging at $4000 \mathrm{rpm}$ for 10 minutes, and the calibration curve was plotted at wavelength $505 \mathrm{~nm}$ and evaluated on the basis of the equation $[\mathrm{Phenol}]=9.11 \times \mathrm{ABS} 505-0.756,(\mathrm{r} 0.99)(8,10)$. In the next step, the Langmuir and Freundlich adsorption isotherms were studied. The following equations were used to determine the adsorption capacity and efficiency $(9): \mathrm{q}_{\mathrm{e}}=\left(\mathrm{C}_{\mathrm{i}}-\mathrm{C}_{\mathrm{e}}\right)^{\mathrm{V}} / \mathrm{w}$; Adsorption $(\%)=\left(\mathrm{C}_{\mathrm{i}}-\mathrm{C}^{\mathrm{e}}\right) / \mathrm{C}_{\mathrm{i}}$

Where: $\mathrm{q}_{\mathrm{e}}=$ adsorption capacity $(\mathrm{mg} / \mathrm{g}), \mathrm{C}_{\mathrm{i}}=$ initial concentration of the adsorbed material in the solution $(\mathrm{mg} / \mathrm{L}), \mathrm{C}_{\mathrm{e}}=$ equilibrium concentration of the adsorbed material after equilibrium takes place $(\mathrm{mg} / \mathrm{L}), \mathrm{V}=$ volume of liquid inside the reactor $(\mathrm{L}), \mathrm{W}=$ Adsorbent mass $(\mathrm{g})$.

\section{Results}




\subsection{Investigation of $\mathrm{pH}$ effect on efficiency of the adsorbent}

Figure 1 illustrates the impact of initial $\mathrm{pH}$ of the solution on phenol adsorption efficiency by pomegranate peel ash. As shown in Figure 1, the maximum phenol removal is obtained as $93.72 \%$ which occurs at $\mathrm{pH}=7$.

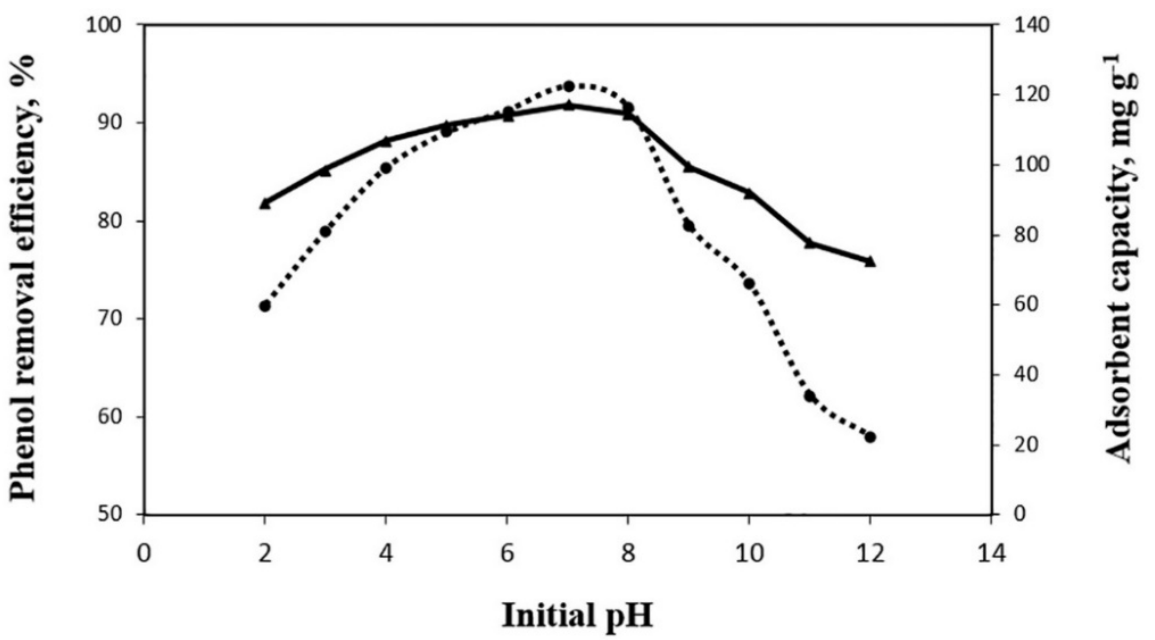

Figure 1. The effect of $\mathrm{pH}$ on phenol adsorption on pomegranate peel (initial phenol concentration $50 \mathrm{mg} / \mathrm{l}$, adsorbent dosage $0.4 \mathrm{~g} / 1$, contact time $60 \mathrm{~min}$ )

\subsection{Effect of the adsorbent dosage}

As observed in Figure 2, the phenol removal efficiency increase from 69.7 to $97.06 \%$ with the increase of the adsorbent dose from 0.1 to $0.7 \mathrm{~g} / \mathrm{L}$. However, the adsorbed phenol rate decreases with respect to each gram of the adsorbent (adsorption capacity). Furthermore, once the adsorbent dose reaches above $0.6 \mathrm{~g} / \mathrm{L}$, a remarkable removal of phenol does not happen. Thus, the optimum dose of the adsorbent was chosen as $0.6 \mathrm{~g} / 1$ and used in the next steps of the experiments.

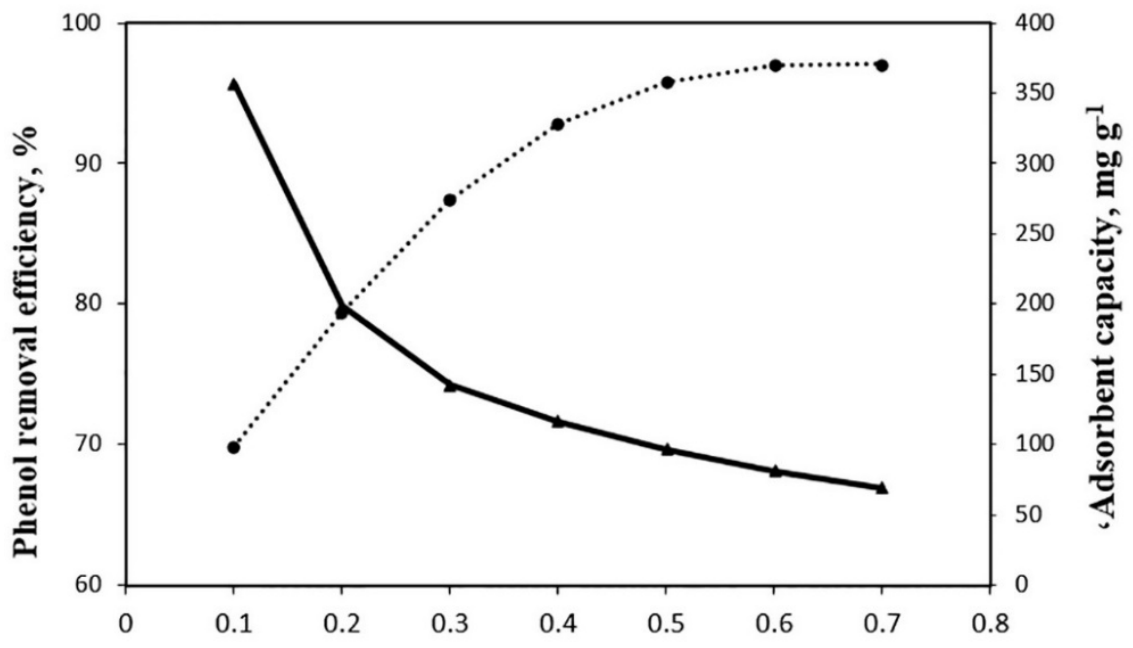

\section{Adsorbent dose $\mathrm{gL}^{-1}$}

Figure 2. The effect of adsorbent dosage on phenol adsorption on pomegranate peel (initial phenol concentration 50 $\mathrm{mg} / \mathrm{l}, \mathrm{pH} 7$, contact time $60 \mathrm{~min}$ )

\subsection{Effect of contact time}

The acquired results from the investigations demonstrate that, the adsorption capacity and phenol removal efficiency increases considerably at initial stages of the adsorption and after approximately 120 minutes reaches the maximum 
amount (95.96\%). The adsorption capacity of pomegranate peel ash was obtained as $79.97 \mathrm{mg} / \mathrm{g}$. Therefore, the retention time of 120 minutes was chosen as the optimum time in this study (Figure 3).

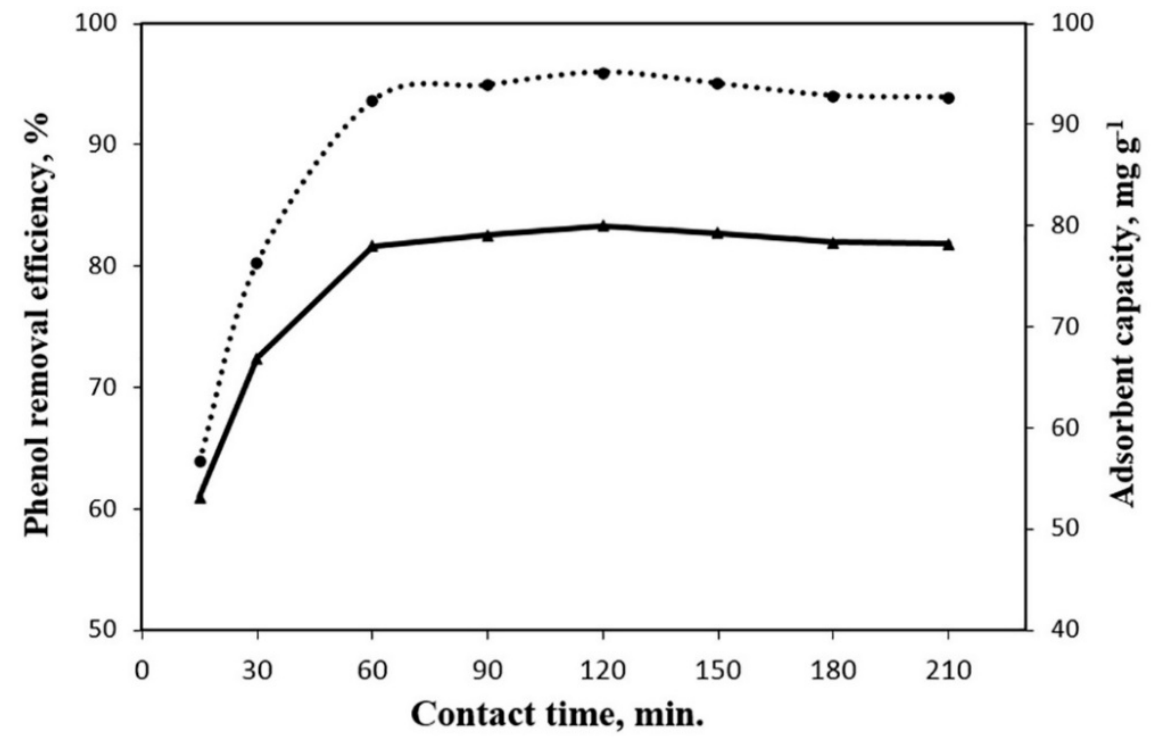

Figure 3. The effect of contact time on phenol adsorption on pomegranate peel (initial phenol concentration $50 \mathrm{mg} / \mathrm{l}$, adsorbent dosage $0.4 \mathrm{~g} / \mathrm{l}$, contact time $60 \mathrm{~min}$ )

\subsection{The effect of initial phenol concentration}

As can be seen in Figure 4, the adsorption capacity of the adsorbent, increases with the increase of phenol concentration and reaches $148.38 \mathrm{mg} / \mathrm{g}$ at initial concentration of $100 \mathrm{mg}$ from $16.43 \mathrm{mg} / \mathrm{g}$ at $10 \mathrm{mg}$. In contrast, the efficiency of phenol removal at the same time period demonstrates a reverse trend.

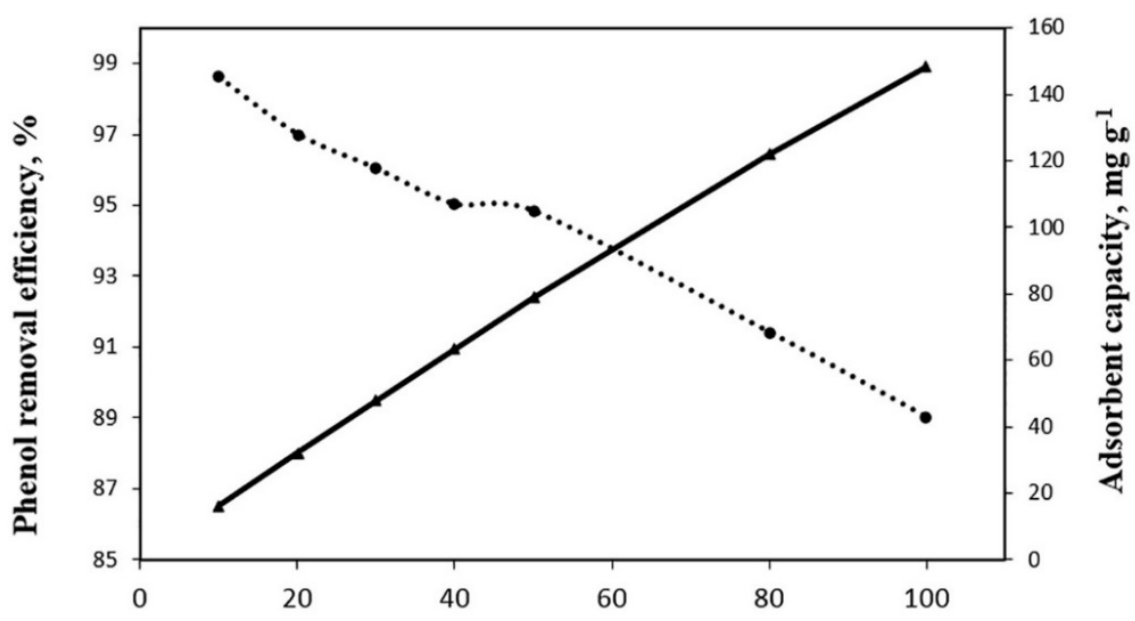

Initial concentration of phenol, $\mathrm{mg} \mathrm{L}^{-1}$

Figure 4. The effect of initial phenol concentration on phenol adsorption (initial phenol concentration $50 \mathrm{mg} / \mathrm{l}$, adsorbent dosage $0.4 \mathrm{~g} / \mathrm{l}$, contact time $120 \mathrm{~min}$ )

\subsection{Adsorption isotherm}

The isotherm models turn experimental results into applicable formulas with useful parameters and make them easy to use in designing processes. Study of the isotherms may help interpret the reactions between the adsorbed material and the adsorbent. In other words, isotherm shows the relationship between concentration of the phenol in solution and the adsorbed phenol rate by solid phase when the two phases are in the equilibrium state. Langmuir and Freundlich equations are widely used in description of adsorption isotherms in solid/liquid systems. In Langmuir theory, 
absorption happens in certain homogeneous places within the absorbent. This model is used to estimate the maximum rate of uptake, the amount of which is obtained in the experiments. However, Freundlich isotherm is based on the adsorption on heterogeneous surfaces and unlike the Langmuir model, does not determine the maximum capacity of the adsorbent. Hence, it is applicable at medium to low concentrations. The isotherms are shown for both models in Figures 5 and 6 based on the experimental data and obtained parameters from non-linear regression.

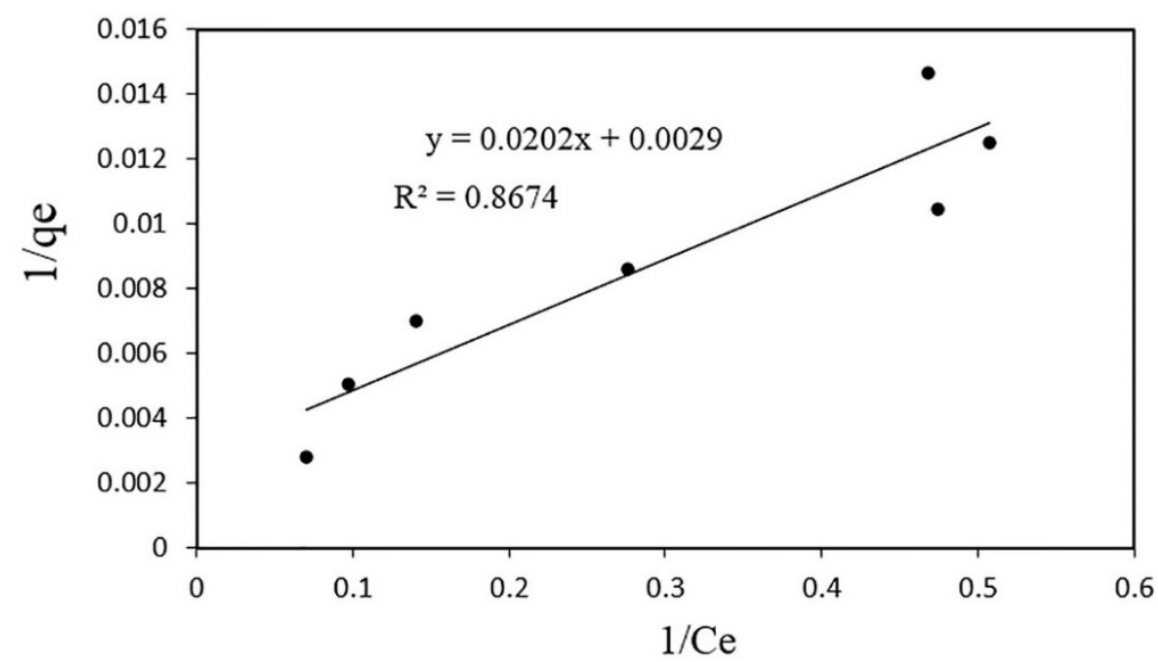

Figure 5. Langmuir isotherm of adsorption

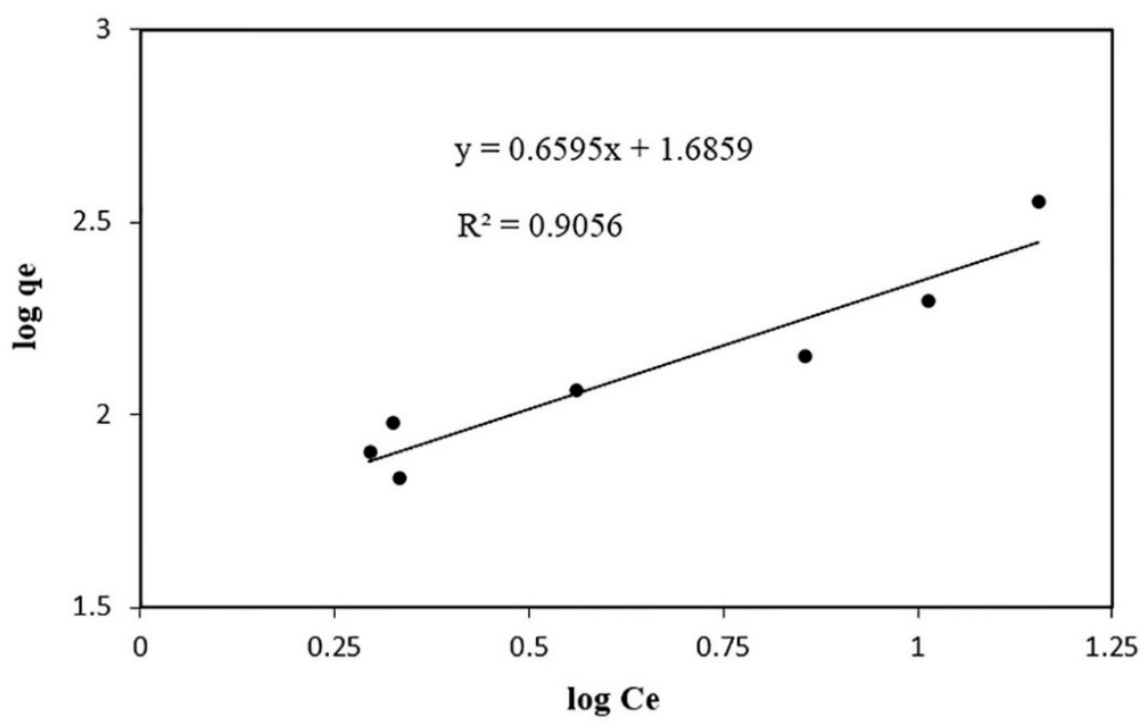

Figure 6. Freundlich of adsorption process

\section{Discussion}

\subsection{The effect of $\mathrm{pH}$}

The $\mathrm{pH}$ of a solution plays an important role in adsorption process, especially in adsorption capacity. This results from the amount of surface charge of the adsorbent, amount of ionization of the material present in the solution as well as separation of the functional groups present in the adsorbing sites of the adsorbent (34). Thus, the adsorption of phenol was studied as a function of hydrogen ion concentration, to determine the effect of the initial $\mathrm{pH}$ variation of the samples on the phenol adsorption process by pomegranate peel ash. The initial $\mathrm{pH}$ values of the samples were adjusted within 2-12 in each series of the experiments. The utilized adsorbent was $0.04 \mathrm{~g}$ in $100 \mathrm{~mL}$ of the solution under experiment and the initial concentration of phenol was $50 \mathrm{mg} \mathrm{L}^{-1}$ in all samples. As inferred from Figure 1 , by increasing the $\mathrm{pH}$ value from 2 to 7 , the phenol removal efficiency also increases to $93.72 \%$ from initial value of $71.4 \%$ and decreases the adsorption on polar adsorbents. Then, following increasing the $\mathrm{pH}$ value above 7 , efficiency 
of the process decreases, as in $\mathrm{pH}=12$ the removal efficiency is obtained as $57.96 \%$. In general, at higher $\mathrm{pH}$ values, adsorption decreases $(\mathrm{pH}>7)$ since phenol is in the form of a salt which loses its negative charge easily, and hence becomes difficult to adsorb. In addition, in this condition, the presence of $\mathrm{OH}^{-}$ions inhibit phenol ions from being adsorbed (35).

\subsection{The effect of adsorbent dosage}

The adsorbent dose is one of the most important parameters which determine the adsorbent capacity for determination of phenol concentration. Therefore, the adsorption experiments were performed using an adsorbent dose in the range of $0.1-0.7 \mathrm{~g}$ in $100 \mathrm{~mL}$ solution containing $50 \mathrm{mg} \mathrm{L}^{-1}$ at optimum $\mathrm{pH}=7$ for sixty minutes at $23 \pm 2{ }^{\circ} \mathrm{C}$, to determine the effect of adsorbent dose on the adsorption process by pomegranate peel ash. As observed in Figure 2, the efficiency of phenol removal has gradually increased up to $97.06 \%$ with a gentle slope, following increasing the adsorbent up to $0.7 \mathrm{~g} / \mathrm{L}$. In other words, there are still sites on the adsorbent which are not saturated during the adsorption process. Considering the fact that, the concentration of phenol is kept constant in all experiments, increasing the amount of the adsorbent has led to enhancing the ratio of the adsorbent to the adsorbed phenol, which provides more surface and sites for adsorption. Furthermore, the results show that, when adsorbent dose reaches above $0.6 \mathrm{mg} / \mathrm{L}$, a remarkable enhance is not observed in phenol adsorption by the adsorbent. It seems, after increasing the adsorbent dose up to a certain amount, the maximum adsorption rate is reached and thus, from this amount on, the remaining amount of the contaminant will stay constant even after addition of more adsorbent (36). Although phenol removal increased by increasing the adsorbent dose, the adsorbed phenol rate per gram of adsorbent decreased, because concentration of dissolved phenol $(50 \mathrm{mg} / \mathrm{L})$ decreased by being adsorbed on unsaturated active sites of the adsorbent. On the other hand, the increase of the adsorbent results in agglomeration of the particles and their adherence to each other (37). Hence, the amount of $0.6 \mathrm{~g} / \mathrm{L}$ of the adsorbent is chosen as the optimum dose of the adsorbent for the rest of the study.

\subsection{The effect of contact time}

The contact time is one of the most important parameters for determination of the equilibrium state of adsorption process. The impact of contact time on the adsorption process was studied at $23 \pm 2{ }^{\circ} \mathrm{C}$, with initial phenol concentration of $50 \mathrm{mg} / \mathrm{L}$ and an adsorbent dose of $0.6 \mathrm{~g} / \mathrm{L}$ in time ranges between 15-210 minutes. Figure 3 depicts the impact of contact time on the adsorption capacity and efficiency of phenol removal by pomegranate peel ash. The adsorption capacity and efficiency of phenol removal increases at first stages of the adsorption remarkably, and then reaches the maximum amount (95.96\%) after 120 minutes. The adsorption capacity of pomegranate peel ash is also obtained as $79.97 \mathrm{mg} / \mathrm{g}$. Therefore, the retention time of 120 minutes is chosen as the equilibrium time. In general, removal of the adsorbed material is fast at first stages of the process, but then decreases gradually until reaching the equilibrium state. This phenomenon may be interpreted as; at the first stages of the adsorption process, there are many available sites on the surface of the adsorbent and over time, the unoccupied sites on the surface of the adsorbent are hardly occupied due to depletion forces between molecules of the adsorbent and the solution phase. On the other hand, the efficiency of phenol removal is high at first stages, because of the high availability of the sites on the surface of the adsorbent for adsorbing the contaminants. Once the sites on the surface of the adsorbent are saturated upon adsorption process, the adsorption rate is controlled by adsorption and desorption of the contaminants on the adsorbent (36). Similar results have been reported by Gengiz and Cavaz (37), and Senthilkumar et al. (38).

\subsection{The effect of initial phenol concentration}

Effect of initial concentration of phenol on the adsorption efficiency was studied at $23 \pm 2{ }^{\circ} \mathrm{C}$ with the adsorption dose of $0.6 \mathrm{~g} / \mathrm{L}$ for 120 minutes. As shown in Figure 4, the adsorption capacity of the adsorbent increases by increasing phenol concentration, whereas the efficiency of phenol removal demonstrates a reverse trend. When initial concentration of phenol increases to $100 \mathrm{~mL}$ from $10 \mathrm{~mL}$, the adsorption capacity increases to $148.38 \mathrm{mg} \mathrm{g}^{-1}$ from $16.43 \mathrm{mg} \mathrm{g}^{-1}$. This may be explained as; with the increase of phenol concentration, the mass transfer driving force and hence the speed of phenol molecules passing through solution to the liquid layer surrounding the adsorbent and finally toward surface of the adsorbent, increases $(40,41)$. On the other hand, the efficiency of phenol removal (removal efficiency) decreases from $98.06 \%$ to $89.03 \mathrm{mg} / \mathrm{L}$ by increasing initial concentration of phenol from $10 \mathrm{mg} / \mathrm{L}$ to 100 $\mathrm{mg} / \mathrm{L}$. This could be attributed to the constant sites for adsorption and increasing the number of molecules of the adsorbed material. In addition, similar results are obtained for phenol adsorption from aqueous solutions by clay and other low price adsorbents (42-48).

\subsection{The isotherms}

Studying the isotherms may help interpret how reactions between the adsorbent and the adsorbed material take place. In other words, an isotherm demonstrates the relationship between phenol concentration of the solution and amount 
of the phenol adsorbed by solid phase when the two phases are in equilibrium state. The Freundlich isotherm is an experimental relationship based on adsorption on heterogeneous surfaces and unlike the Langmuir model, does not specify the maximum adsorption capacity and thus, is applicable only at medium or low concentrations (49-51). The isotherms are shown in Figures 5 and 6 for both models on the basis of experimental data and parameters resulted from nonlinear regression. The correlation coefficient of the Langmuir model $\left(\mathrm{R}^{2}=0.8674\right)$ is lower than that of the Freundlich model $\left(\mathrm{R}^{2}=0.9056\right)$ which indicates the fact that the Freundlich model is more suitable for interpretation of equilibrium adsorption of phenol on pomegranate peel ash. On the other hand, once the parameter $1 / \mathrm{n}$ value is in between $0.1-1$, it shows appropriate adherence to the Freundlich isotherm and indicates that the adsorption is pleasant as was in this study.

\section{Conclusions}

The acquired results demonstrated that pomegranate peel ash shows good capability for removal of phenol from aqueous solutions. The adsorption rate will increase by increasing the amount of the adsorbent due to contact surface increase. At higher concentrations of phenol, a decrease in adsorption rate was observed. The adsorption capacity obtained as $148.38 \mathrm{mg} / \mathrm{g}$ when applying $0.6 \mathrm{~g}$ pomegranate peel ash for removal of phenol from $100 \mathrm{~mL}$ of solution containing $100 \mathrm{mg}$ of phenol in 120 minutes at $\mathrm{pH}=7$. Furthermore, it was observed that, pomegranate peel ash is capable of removing more than $98 \%$ of the phenol from aqueous solutions with initial concentrations in between 10 $100 \mathrm{mg} / \mathrm{L}$. On the other hand, the obtained experimental results in this study were evaluated by two well-known models, Freundlich and Langmuir, and the coefficient values acquired indicate that the Freundlich model is more appropriate compared to the Langmuir model.

\section{Acknowledgments:}

The authors gratefully acknowledge the Research Council of Gonabad University of Medical Sciences (GN 94/61), also from respectable personnel of the Gonabad municipality and environmental protection organization.

\section{Conflict of Interest:}

There is no conflict of interest to be declared.

\section{Authors' contributions:}

All authors contributed to this project and article equally. All authors read and approved the final manuscript.

\section{References:}

1) Rappoport Z. The Chemistry of Phenols, John Wiley \& Sons, Ltd. 2003. doi: 10.1002/0470857277.

2) Pan G, Kurumada KI. Hybrid gel reinforced with coating layer for removal of phenol from aqueous solution. Chemical Engineering Journal. 2008; 138(1-3): 194-9. doi: 10.1016/j.cej.2007.06.025.

3) Busca G, Berardinelli S, Resini C, Arrighi L. Technologies for the removal of phenol from fluid streams: a short review of recent developments. J Hazard Mater. 2008; 160(2-3): 265-88. doi: 10.1016/j.jhazmat.2008.03.045. PMID: 18455866.

4) Ersöz A, Denizli A, Şener İ, Atılır A, Diltemiz S, Say R. Removal of phenolic compounds with nitrophenolimprinted polymer based on $\pi-\pi$ and hydrogen-bonding interactions. Separation and purification technology. 2004; 38(2): 173-9. doi: 10.1016/j.seppur.2003.11.004.

5) Kinsley C, Nicell JA. Treatment of aqueous phenol with soybean peroxidase in the presence of polyethylene glycol. Bioresource Technology. 2000; 73(2): 139-46. doi: 10.1016/S0960-8524(99)00151-0.

6) Karel V. Handbook of environmental data on organic chemicals. 2000; 2. John Wiley and Sons Inc, Canada.

7) Raynold J E F. Martindale the extra,pharmacopocia disinfectants and antiseptics, 1982, 28th Ed. landan. 5702.

8) Jalali M, Nikravesh MR. The Study of Phenol Interventional Effects on Mouse Organogenesis. Pharmaceutical Sciences. 2001; 18(1): 15-22.

9) Mohammadi AS, Mohammadi G. 4-Chlorophenol oxidation combined with the application of advanced oxidation technology and the modified microwave in chemical and petrochemical wastewater industry. Proceedings of the 1th Iranian Petrochemical Conference. 2008. 2008: 194.

10) Rengaraj S, Moon SH, Sivabalan R, Arabindoo B, Murugesan V. Removal of phenol from aqueous solution and resin manufacturing industry wastewater using an agricultural waste: rubber seed coat. J Hazard Mater. 2002; 89(2-3): 185-96. doi: 10.1016/s0304-3894(01)00308-9. PMID: 11744204.

11) Bódalo A, Gómez E, Hidalgo AM, Gómez M, Murcia MD, López I. Nanofiltration membranes to reduce phenol concentration in wastewater. Desalination. 2009; 245(1): 680-6. doi: 10.1016/j.desal.2009.02.037. 
12) Aksu Z, Yener J. A comparative adsorption/biosorption study of mono-chlorinated phenols onto various sorbents. Waste Manag. 2001; 21(8): 695-702. PMID: 11699627.

13) Viraraghavan T, de Maria Alfaro F. Adsorption of phenol from wastewater by peat, fly ash and bentonite. Journal of Hazardous Materials. 1998; 57(1-3): 59-70. doi: 10.1016/S0304-3894(97)00062-9.

14) Balasubramanian A, Venkatesan S. Removal of phenolic compounds from aqueous solutions by emulsion liquid membrane containing ionic liquid [BMIM]+[PF 6]-in tributyl phosphate. Desalination. 2012; 289(15): 27-34. doi: 10.10 16/j. desal.20 11.12.027.

15) Bazrafshan E, Biglari H, Mahvi AH. Phenol removal by electrocoagulation process from aqueous solutions. Fresenius Environmental Bulletin. 2012; 21(2): 364-71.

16) Biglari $\mathrm{H}$, Bazrafshan $\mathrm{E}$. Phenol removal from synthetic aqueous environment by electrochemical process using iron and aluminum electrodes. Iranian Journal of Health \& Environment. 2011; 4(5): 531-42.

17) Li HQ, Han HJ, Du MA, Wang W. Removal of phenols, thiocyanate and ammonium from coal gasification wastewater using moving bed biofilm reactor. Bioresource technology. 2011; 102(7): 4667-73. doi: 10.1016/j.biortech.2011.01.029. PMID: 21320775.

18) Jamshidi N, Torabian A, Azimi A, NabiBidhendi GR, Jafarzadeh MT. Investigation of phenol removal in aqueous solutions using advanced photochemical oxidation (APO). J of Water and Wastewater. 2009; 72: 24-9.

19) Li X, Chen S, Fan X, Quan X, Tan F, Zhang Y, Gao J. Adsorption of ciprofloxacin, bisphenol and 2chlorophenol on electrospun carbon nanofibers: In comparison with powder activated carbon. J Colloid Interface Sci. 2015; 447: 120-7. doi: 10.1016/j.jcis.2015.01.042. PMID: 25702869.

20) Rodrigues LA, da Silva ML, Alvarez-Mendes MO, dos Reis Coutinho A, Thim GP. Phenol removal from aqueous solution by activated carbon produced from avocado kernel seeds. Chemical Engineering Journal. 2011; 174(1): 49-57. doi: 10.1016/j.cej.2011.08.027.

21) Suresh S, Srivastava VC, Mishra IM. Adsorptive removal of phenol from binary aqueous solution with aniline and 4-nitrophenol by granular activated carbon. Chemical engineering journal. 2011; 171(3): $997-$ 1003. doi: 10.1016/j.cej.2011.04.050.

22) El-Naas MH, Al-Zuhair S, Alhaija MA. Reduction of COD in refinery wastewater through adsorption on date-pit activated carbon. J Hazard Mater. 2010; 173(1-3): 750-7. doi: 10.1016/j.jhazmat.2009.09.002. PMID: 19783364.

23) Senturk HB, Ozdes D, Gundogdu A, Duran C, Soylak M. Removal of phenol from aqueous solutions by adsorption onto organomodified Tirebolu bentonite: Equilibrium, kinetic and thermodynamic study. Journal of Hazardous Materials. 2009; 172(1): 353-62. doi: 10.1016/j.jhazmat.2009.07.019. PMID: 19656623.

24) Hameed BH, Rahman AA. Removal of phenol from aqueous solutions by adsorption onto activated carbon prepared from biomass material. J Hazard Mater. 2008; 160(2): 576-81. doi: 10.1016/j.jhazmat.2008.03.028. PMID: 18434009.

25) Özkaya B. Adsorption and desorption of phenol on activated carbon and a comparison of isotherm models. J Hazard Mater. 2006; 129(1-3): 58-63. doi: 10.1016/j.jhazmat.2005.08.025. PMID: 16198050.

26) Stavropoulos GG, Samaras P, Sakellaropoulos GP. Effect of activated carbons modification on porosity, surface structure and phenol adsorption. Journal of Hazardous Materials. 2008; 151(2): 414-21. doi: 10.1016/j.jhazmat.2007.06.005. PMID: 17644248.

27) Alkaram UF, Mukhlis AA, Al-Dujaili AH. The removal of phenol from aqueous solutions by adsorption using surfactant-modified bentonite and kaolinite. J Hazard Mater. 2009; 169(1-3): 324-32. doi: 10.1016/j.jhazmat.2009.03.153. PMID: 19464105.

28) Ming ZW, Long CJ, Cai PB, Xing ZQ, Zhang B. Synergistic adsorption of phenol from aqueous solution onto polymeric adsorbents. Journal of hazardous materials. 2006; 128(2-3): 123-9. doi: 10.1016/j.jhazmat.2005.03.036. PMID: 16457950.

29) Yousef RI, El-Eswed B. The effect of $\mathrm{pH}$ on the adsorption of phenol and chlorophenols onto natural zeolite. Colloids and Surfaces A: Physicochemical and Engineering Aspects. 2009; 334(1-3): 92-9. doi: 10.1016/j.colsurfa.2008.10.004.

30) Saitoh T, Asano K, Hiraide M. Removal of phenols in water using chitosan-conjugated thermo-responsive polymers. J Hazard Mater. 2011; 185(2-3): 1369-73. doi: 10.1016/j.jhazmat.2010.10.057. PMID: 21074940.

31) Dursun AY, Kalayci CS. Equilibrium, kinetic and thermodynamic studies on the adsorption of phenol onto chitin. J Hazard Mater. 2005; 123(1-3): 151-7. doi: 10.1016/j.jhazmat.2005.03.034. PMID: 15993297.

32) Lin $\mathrm{K}$, Pan J, Chen $\mathrm{Y}$, Cheng R, Xu X. Study the adsorption of phenol from aqueous solution on hydroxyapatite nanopowders. J Hazard Mater. 2009; 161(1): 231-40. doi: 10.1016/j.jhazmat.2008.03.076. PMID: 18573599. 
33) Glesceria LA, Greenberg E, Eaton AD. Standardmethods for the examination of water and wastewater. 31st ed. Washington DC: APHA, 2005.

34) Rasoulifard MH, Qazvini NT, Farhangnia E, Heidari A, Mohamadi SD. Removal of direct yellow 9 and reactive orange 122 from contaminated water using chitosan as a polymeric bioadsorbent by adsorption process. J Color Sci Tech. 2010; 4(1): 17-23.

35) Rengaraj S, Moon SH, Sivabalan R, Arabindoo B, Murugesan V. Agricultural solid waste for the removal of organics: adsorption of phenol from water and wastewater by palm seed coat activated carbon. Waste Manag. 2002; 22(5): 543-8. doi: 10.1016/S0956-053X(01)00016-2. PMID: 12092764.

36) Chakravarty P, Sarma NS, Sarma HP. Removal of lead (II) from aqueous solution using heartwood of Areca catechu powder. Desalination. 2010; 256(1): 16-21. doi: 10.1016/j.desal.2010.02.029.

37) Calvete T, Lima EC, Cardoso NF, Dias SL, Pavan FA. Application of carbon adsorbents prepared from the Brazilian pine-fruit-shell for the removal of Procion Red MX 3B from aqueous solution-Kinetic, equilibrium, and thermodynamic studies. J Environ Manage. 2009; 91(8): 1695-706. doi: 10.1016/j.jenvman.2010.03.013. PMID: 20398999.

38) Cengiz S, Cavas L. Removal of methylene blue by invasive marine seaweed: Caulerparacemosa var. cylindracea. Bioresour Technol. 2008; 99(7): 2357-63. doi: 10.1016/j.biortech.2007.05.011. PMID: 17604623.

39) SenthilKumar P, Ramalingam S, Sathyaselvabala V, Kirupha SD, Sivanesan S. Removal of copper (II) ions from aqueous solution by adsorption using cashew nut shell. Desalination. 2011; 266(1-3): 63-71. doi: 10.1016/j.desal.2010.08.003.

40) Caturla F, Martin-Martinez JM, Molina-Sabio M, Rodriguez-Reinoso F, Torregrosa R. Adsorption of substituted phenols on activated carbon. Journal of colloid and interface science. 1988; 124(2): 528-34. doi: 10.1016/0021-9797(88)90189-0.

41) Imagawa A, Seto R, Nagaosa Y. Adsorption of chlorinated hydrocarbons from air and aqueous solutions by carbonized rice husk. Carbon. 2000; 38(4): 628-30. doi: 10.1016/S0008-6223(00)00006-3.

42) Nayak PS, Singh BK. Removal of phenol from aqueous solutions by sorption on low cost clay. Desalination. 2007; 207(1-3): 71-9. doi: 10.1016/j.desal.2006.07.005.

43) Bhatnagar A. Removal of bromophenols from water using industrial wastes as low cost adsorbents. J Hazard Mater. 2007; 139(1): 93-102. doi: 10.1016/j.jhazmat.2006.06.139. PMID: 16938394.

44) Karaoğlu MH, Doğan M, Alkan M. Removal of cationic dyes by kaolinite. Microporous and Mesoporous Materials. 2009; 122(1-3): 20-7. doi: 10.1016/j.micromeso.2009.02.013.

45) Tsai WT, Hsu HC, Su TY, Lin KY, Lin CM. Removal of basic dye (methylene blue) from wastewaters utilizing beer brewery waste. Journal of Hazardous Materials. 2008; 154(1-3): 73-8. doi: 10.1016/j.jhazmat.2007.09.107. PMID: 18006225.

46) Cruz CC, da Costa AC, Henriques CA, Luna AS. Kinetic modeling and equilibrium studies during cadmium biosorption by dead Sargassum sp. biomass. Bioresour Technol. 2004; 91(3): 249-57. doi: 10.1016/S09608524(03)00194-9. PMID: 14607484.

47) Yarmohammadi H, Hamidvand E, Abdollahzadeh D, Sohrabi Y, Poursadeghiyan M, Biglari H, et al. Measuring concentration of welding fumes in respiratory zones of welders: An ergo-toxicological approach. Research Journal of Medical Sciences. 2016; 10(3): 111-5. doi: 10.3923/rjmsci.2016.111.115.

48) Biglari H, Sohrabi Y, Charganeh SS, Dabirian M, Javan N. Surveying the geographical distribution of aluminium concentration in groundwater resources of sistan and baluchistan, Iran. Research Journal of Medical Sciences. 2016; 10(4): 351-4. doi: 10.3923/rjmsci.2016.351.354.

49) Yarmohammadi H, Poursadeghiyan M, Shorabi Y, Ebrahimi MH, Rezaei G, Biglari H, et al. Risk assessment in a wheat winnowing factory based on ET and BA method. Journal of Engineering and Applied Sciences. 2016; 11(3): 334-8. doi: 10.3923/jeasci.2016.334.338.

50) Biglari H, Chavoshani A, Javan N, Hossein Mahvi A. Geochemical study of groundwater conditions with special emphasis on fluoride concentration, Iran. Desalination and Water Treatment. 2016; 47(57): 1-8. doi: 10.1080/19443994.2015.1133324.

51) Alipour V, Dindarloo K, Mahvi AH, Rezaei L. Evaluation of corrosion and scaling tendency indices in water distribution system: a case study of Torbat Heydariye, Iran. J Water Health. 2015; 13(1): 203-9. doi: 10.2166/wh.2014.157. PMID: 25719479. 